\title{
BROMATOLOGIA E DIGESTIBILIDADE DE GRAMÍNEAS MANEJADAS POR CORTE SUBMETIDAS A DIFERENTES LÂMINAS DE IRRIGAÇÃO
}

Carlos Augusto Brasileiro de Alencar ${ }^{1}$, Carlos Eugênio Martins², Antônio Carlos Cóser ${ }^{2}$, Rubens Alves de Oliveira Fernando França da Cunha ${ }^{3}$

\section{RESUMO}

Objetivou-se, neste trabalho, avaliar a composição bromatológica e a digestibilidade in vitro da matéria seca (DIVMS) de seis gramíneas manejadas por corte, sob efeito de diferentes lâminas de irrigação. O experimento foi conduzido em esquema de parcelas subdivididas, tendo nas parcelas seis gramíneas (Xaraés, Mombaça, Tanzânia, Pioneiro, Marandu e Estrela) e, nas subparcelas, seis lâminas de irrigação $(0,18,45,77,100$ e $120 \%$ da referência), no delineamento inteiramente casualizado, com duas repetições. Para diferenciar a aplicação das lâminas de irrigação, utilizou-se o sistema por aspersão em linha. Foram avaliados os teores de proteína bruta (PB), o de fibra em detergente neutro (FDN) e a digestibilidade in vitro da matéria seca (DIVMS) e suas obtenções foram de acordo com a literatura. O capim-estrela apresentou maior teor de PB e FDN e menor DIVMS. O capim-marandu apresentou a maior DIVMS. O aumento da lâmina de irrigação reduziu o teor de PB e dependeu da forrageira para exercer efeito no teor de FDN e na DIVMS. A lâmina de irrigação não afetou os teores de FDN dos capins Mombaça e Tanzânia e proporcionou efeito quadrático nos demais capins. Esse mesmo fator reduziu a DIVMS do capim-mombaça, proporcionou efeito quadrático nos capins Tanzânia e Marandu e não afetou as demais forrageiras.

Palavras-chave: proteína bruta, fibra em detergente neutro, B. brizantha, C. nlemfuensis, P. maximum, P. purpureum

\section{CHEMICAL COMPOSITION AND DIGESTIBILITY OF THE GRASSES CULTIVATED UNDER CUT SUBMITTED THE DIFFERENT IRRIGATION DEPTHS}

\begin{abstract}
It was aimed to evaluate the chemical composition and in vitro dry matter digestibility (IVDMD) of six grasses under different irrigation depths. The experiment was conducted in a completely randomized arrangement, with two replications, in a split plot design. Six grasses (Xaraes, Mombaça, Tanzania, Pioneiro, Marandu and Estrela) constituted the plots and six irrigation depths $(0 \%, 18 \%, 45 \%, 77 \%, 100 \%$ and $120 \%$ of the reference) the split-plots. To vary the application of irrigation depths it was used the line source sprinkler system. Were evaluated the crude protein (CD), neutral detergent fiber (NDF) and IVDMD and its obtainings went in agreement with to literature. Estrela grass presented larger CD and NDF and smaller IVDMD. The Marandu grass presented largest IVDMD. The increase of the irrigation depths reduced the $\mathrm{CD}$ and it depended on the grasses to check effect in the NDF and in IVDMD. The irrigation depths didn't affect the NDF of the Mombaça and Tanzania and it provided quadratic effect us other grasses. That same factor reduced IVDMD of the Mombaça grass, it provided quadratic effect in the Tanzania and Marandu and it didn’t affect the other grasses.
\end{abstract}

Keywords: crude protein, neutral detergent fiber, B. brizantha, C. nlemfuensis, P. maximum, P. purpureum

\section{Recebido para publicação em 02/03/2010. Aprovado em 13/04/2010}

1- Pesquisador DEA/UFV. Rua Senador Vaz de Melo. 36.570-000, Viçosa, MG. E-mail: c.brasileiro@yahoo.com.br

2- Pesquisador CNPGL/EMBRAPA. Rua Eugênio do Nascimento, 610. CEP: 36038-330, Juiz de Fora, MG. E-mail: caeuma@cnpgl. embrapa.br, acoser@cnpgl.embrapa.br

3- Professor DEA/UFV. Av. Peter Henry Rolfs, s/n, CEP: 36570-000, Viçosa, MG. E-mail: rubens@ufv.br, fcunha@vicosa.ufv.br 


\section{INTRODUÇÃO}

No leste do Estado de Minas Gerais, a pecuária de corte e leite exerce forte influência na economia regional. Essa região tem um rebanho de 1,6 milhão de cabeças e 0,6 milhão de hectares de pastagens cultivadas, representando $25 \%$ do total dessas pastagens. Possui uma densidade bovina de 0,7 cabeça por hectare, abaixo da média do Estado (IBGE, 2005).

O desempenho dos ruminantes está diretamente ligado à quantidade de nutrientes ingeridos, os quais são necessários para atender às exigências de manutenção e produção animal (GOMIDE, 1993). Para isso, esses ruminantes devem consumir pastagens que possuam matéria seca em quantidade e qualidade, destacando-se os cultivares dos gêneros Pennisetum, Cynodon, Panicum e Brachiaria. A região leste do Estado de Minas Gerais apresenta grande potencial para o uso dessas forrageiras.

As irregularidades do regime pluvial tornamse uma restrição ao desenvolvimento de plantas forrageiras, pois, mesmo dentro de estações chuvosas, observam-se períodos de deficit hídrico, pois a evapotranspiração da pastagem geralmente excede a precipitação pluvial (CUNHA et al., 2007). O manejo da irrigação é um recurso para racionalizar a aplicação de água às culturas, de maneira complementar às precipitações pluviais, necessitando-se de procedimentos técnicos para determinar o turno de rega e a quantidade de água a aplicar (RASSINI, 2001). Assim, a reposição de água ao solo, por meio da irrigação, na quantidade adequada e no momento oportuno, é decisiva para o sucesso da intensificação da produção.

O uso da irrigação de pastagens vem crescendo, principalmente na região Centro-Oeste. Já existem aproximadamente 80 pivôs centrais irrigando áreas de 100 ha cada, em média, na região central do Brasil (VILELA, 1999). Segundo o mesmo autor, $25 \%$ das vendas de equipamentos tipo pivô central são destinadas à pecuária.

O valor nutritivo da forragem, ao longo do ano, em áreas irrigadas é diferente, quando comparado com a de pastagens não irrigadas. Segundo Gerdes et al. (2000), o conceito do termo "valor nutritivo" refere-se à composição química da forragem e a sua digestibilidade.

A proteína bruta $(\mathrm{PB})$ das plantas forrageiras inclui tanto a proteína verdadeira quanto o nitrogênio não proteico. A proteína verdadeira, dependendo da maturidade da planta, pode representar até $70 \%$ da PB nas forragens verdes, ou seja, quando a forragem ainda é nova (HEATH et al., 1985). A irrigação das pastagens propicia aumento do teor de PB. Vanzela et al. (2006), trabalhando com capim-mombaça, na região oeste do Estado de São Paulo, observaram que os teores de PB variaram de 9,7 a $13,8 \%$, no cultivo em sequeiro, e de 10,1 a $14,9 \%$, no cultivo irrigado. Cunha et al. (2007) encontraram resultados diferentes para o capim-tanzânia, no município de Viçosa, MG. Esses autores observaram redução do teor de PB conforme se aumentava a lâmina de irrigação.

A digestibilidade é a medida da proporção do alimento consumido que é digerida e metabolizada pelo animal. Em princípio, a digestibilidade potencial de todos os componentes da planta, exceto a lignina, é de $100 \%$, contudo, a digestão completa nunca acontece, por causa das incrustações de hemicelulose e celulose pela lignina, que tem efeito protetor contra a ação dos micro-organismos do rúmen (WHITEMAN, 1980).

Segundo Van Soest (1994), a fibra em detergente neutro (FDN) é o componente da forragem mais consistentemente associado ao consumo. Os componentes indigestíveis de um alimento são recuperados na FDN, enquanto o detergente ácido divide a FDN nas frações solúvel e insolúvel em ácido sulfúrico a $1 \mathrm{~N}$. A fração solúvel em ácido compreende a hemicelulose e as proteínas da parede celular. Segundo Wilson (1983) e Halim et al. (1989), a irrigação aumenta a qualidade das forragens pela redução da FDN.

A digestibilidade in vitro da matéria seca (DIVMS) apresenta correlação com o consumo voluntário. Baixa digestibilidade implica em maior tempo de retenção da forragem no rúmen, promovendo limitações de consumo de ordem física. Cerca de 40 a $60 \%$ das variações de consumo entre as forrageiras podem ser atribuídas às diferenças na digestibilidade (REIS \& RODRIGUES, 1993). A DIVMS das pastagens é afetada pela irrigação. Gerdes et al. (2005), cultivando capim-aruana exclusivo e sobressemeado, com mistura de aveia preta e azevém, esperavam maiores valores de DIVMS no tratamento sobre-semeado, porém, não encontraram diferença significativa, justificando esse efeito pela irrigação ministrada ao capim-aruana exclusivo.

No presente trabalho, objetivou-se avaliar os efeitos de diferentes lâminas de irrigação sobre a 
composição bromatológica e a digestibilidade in vitro da matéria seca de seis gramíneas forrageiras, manejadas sob corte, na região leste do Estado de Minas Gerais.

\section{MATERIAL E MÉTODOS}

Este trabalho foi realizado de maio de 2003 a abril de 2005, na Universidade Vale do Rio Doce, localizada no município de Governador Valadares, MG, sendo, as coordenadas geográficas, $18^{\circ} 47^{\prime}$ 30 " de latitude sul e $41^{\circ} 59^{\prime}$ '04" de longitude oeste e, a altitude, de $223 \mathrm{~m}$.

As médias de precipitação e evapotranspiração potencial de referência, durante os dois anos de experimento, foram de $1064 \mathrm{~mm}$ e $1277 \mathrm{~mm}$, respectivamente. $\mathrm{O}$ solo na área experimental foi classificado como Cambissolo eutrófico, textura média, com a seguinte composição química na camada de 0 a $30 \mathrm{~cm}: \mathrm{pH}\left(\mathrm{H}_{2} \mathrm{O}\right)=6,5 ;$ M.O. $=1,6 \mathrm{~g}$ $\mathrm{dm}^{-3} ; \mathrm{P}=6,0 \mathrm{mg} \mathrm{dm}^{-3} ; \mathrm{K}^{+}=60 \mathrm{mg} \mathrm{dm}{ }^{-3} ; \mathrm{Ca}^{+2}=3,8$ $\mathrm{cmol}_{\mathrm{c}} \mathrm{dm}^{-3} ; \mathrm{Mg}^{+2}=1,0 \mathrm{cmol}_{\mathrm{c}} \mathrm{dm}^{-3} ; \mathrm{Al}^{+3}=0,1 \mathrm{cmol}_{\mathrm{c}}$ $\mathrm{dm}^{-3} ; \mathrm{H}+\mathrm{Al}=4,0 \mathrm{cmol}_{\mathrm{c}} \mathrm{dm}^{-3} \mathrm{e} \mathrm{V}=55 \%$. A adubação de plantio consistiu em $100 \mathrm{~kg} \mathrm{ha}^{-1}$ de $\mathrm{P}_{2} \mathrm{O}_{5}$, cuja fonte foi superfosfato simples, sendo aplicado todo o fósforo no fundo do sulco. A adubação total consistiu em $50 \mathrm{~kg} \mathrm{ha}^{-1}$ ano $^{-1}$ de $\mathrm{P}_{2} \mathrm{O}_{5}, 150 \mathrm{~kg} \mathrm{ha}^{-1}$ $\mathrm{ano}^{-1}$ de $\mathrm{K}_{2} \mathrm{O}$ e $300 \mathrm{~kg} \mathrm{ha}^{-1} \mathrm{ano}^{-1}$ de $\mathrm{N}$, tendo como fontes o superfosfato simples, o cloreto de potássio e a ureia, respectivamente, sendo aplicado todo o fósforo em cobertura a cada ano. $\mathrm{O}$ cloreto de potássio e a ureia foram aplicados em cobertura, parcelada em seis vezes ao ano, até o final do experimento.

A distribuição granulométrica e os resultados das análises físico-hídricas do solo foram os seguintes: argila $=30 \%$; silte $=25 \%$; areia $=45 \%$; capacidade de campo $=0,30 \mathrm{~g} \mathrm{~g}^{-1}$; ponto de murcha $=0,17 \mathrm{~g} \mathrm{~g}^{-1}$ e densidade do solo $=1,38 \mathrm{~g} \mathrm{~cm}^{-3}$. A densidade do solo foi determinada pelo método do anel volumétrico, descrito pela EMBRAPA (1997), e os níveis de umidade do solo na capacidade de campo e no ponto de murcha permanente foram determinados para as tensões de 10 e $1500 \mathrm{kPa}$, respectivamente. Os valores de retenção de água no solo foram determinados utilizando-se o método da Câmara de Richards (RICHARDS, 1949).

O experimento foi conduzido em esquema de parcelas subdivididas, tendo nas parcelas as gramíneas (Brachiaria brizantha cv. Xaraés, Panicum maximum cv. Mombaça, Panicum maximum cv. Tanzânia, Pennisetum purpureum cv. Pioneiro, Brachiaria brizantha cv. Marandu e Cynodon nlemfuensis L. cv. Estrela) e, nas subparcelas, as lâminas de irrigação $(0,95,236$, 404,525 e $630 \mathrm{~mm}^{2}$ ano $^{-1}$, correspondendo a 0,18 , $45,77,100$ e $120 \%$ da referência, respectivamente), no delineamento inteiramente casualizado, com duas repetições.

As semeaduras foram realizadas manualmente, em fileiras espaçadas de $30 \mathrm{~cm}$, com sementes distribuídas na profundidade média de $2 \mathrm{~cm}$. Nos casos dos cultivares dos gêneros Cynodon e Pennisetum, que não produzem sementes, a formação da forrageira foi por via vegetativa, com distribuição das mudas em sulcos espaçados de $50 \mathrm{~cm}$ e nas profundidades de 10 e $15 \mathrm{~cm}$, respectivamente. No plantio do cultivar do gênero Cynodon, dois terços da muda foram enterrados, deixando-se o terço apical sobre o solo.

As parcelas experimentais tinham $6 \mathrm{~m}$ de largura e $18 \mathrm{~m}$ de comprimento e foram subdivididas em seis partes iguais, resultando em subparcelas de $6 \mathrm{x}$ $3 \mathrm{~m}\left(18 \mathrm{~m}^{2}\right)$. As lâminas de água foram originadas das diferentes distribuições de água na direção perpendicular à tubulação com os aspersores. Para isso, foi utilizado o sistema de irrigação por aspersão com distribuição dos aspersores em linha (Line Source Sprinkler System), conforme Hanks et al. (1976). A lâmina de irrigação de referência $(100 \%)$ foi determinada por meio do monitoramento do potencial de água no solo, feito por tensiômetro de punção com tensímetro digital, instalado a 15 e $45 \mathrm{~cm}$ de profundidade. As irrigações foram efetuadas quando os tensiômetros, instalados a 15 $\mathrm{cm}$, registraram valores de potencial matricial em torno de $-60 \mathrm{kPa}$. A lâmina de irrigação aplicada foi medida com pluviômetros instalados em cada subparcela experimental e calculada por meio da equação:

$$
\mathrm{L}=\frac{(\mathrm{CC}-\theta)}{10} \mathrm{D} \mathrm{Z} \frac{1}{\mathrm{Ea}}
$$

em que,

$\mathrm{L}=$ lâmina total necessária $(\mathrm{mm})$;

$\mathrm{CC}=$ capacidade de campo (\% em massa);

$\theta=$ teor de água do solo, no potencial matricial de

$-60 \mathrm{kPa}(\%$ em massa);

$\mathrm{D}=$ densidade do solo $\left(\mathrm{g} \mathrm{cm}^{-3}\right)$;

$\mathrm{Z}=$ profundidade efetiva do sistema radicular $(\mathrm{cm})$;

$\mathrm{Ea}=$ eficiência de aplicação de água (decimal). 
Simultaneamente ao monitoramento da umidade do solo via tensiometria, foram coletados dados meteorológicos diários, a partir de uma estação meteorológica automática, instalada dentro da área experimental.

$\mathrm{O}$ experimento foi conduzido sob manejo de corte. As coletas de forragem foram realizadas,manualmente, em intervalos de 50 dias, sendo a altura de corte de $20 \mathrm{~cm}$ em relação ao nível do solo. Em uma área delimitada por uma unidade amostral metálica, de forma retangular e com o tamanho de $1,0 \times 0,5 \mathrm{~m}$ (área útil de $0,5 \mathrm{~m}^{2}$ ). Toda a massa verde colhida foi acondicionada em sacos, devidamente identificados e imediatamente pesados. Em seguida, o material foi secado em estufa com circulação de ar a $60^{\circ} \mathrm{C}$, por um período de 72 horas.

A avaliação da composição bromatológica e da digestibilidade in vitro da matéria seca (DIVMS) foi feita apenas nas estações primavera e verão. As amostras colhidas nessas estações foram juntadas para serem moídas em moinho do tipo Willey, em peneira de malha de um milímetro, e acondicionadas em recipientes devidamente identificados.
Os teores de proteína bruta (PB) e de fibra em detergente neutro (FDN) foram determinados segundo métodos descritos por Silva \& Queiroz (2002) e a DIVMS, segundo técnica descrita por Tilley \& Terry (1963). Essas determinações foram realizadas no Centro Nacional de Pesquisa de Gado de Leite, da Empresa Brasileira de Pesquisa Agropecuária.

Os dados foram submetidos às análises de variância e de regressão. A comparação de médias foi realizada utilizando-se o teste de Tukey a $5 \%$ de probabilidade. Para o fator quantitativo, os modelos foram escolhidos com base na significância dos coeficientes de regressão, utilizando-se o teste t a $10 \%$ de probabilidade, no coeficiente de determinação $\left(\mathrm{R}^{2}\right)$ e no fenômeno biológico. Para execução das análises estatísticas, foi utilizado o programa estatístico SAEG 9.0.

\section{RESULTADOS E DISCUSSÃO}

Os valores médios mensais dos elementos meteorológicos obtidos durante o período estudado estão apresentados nas Figuras 1 e 2.

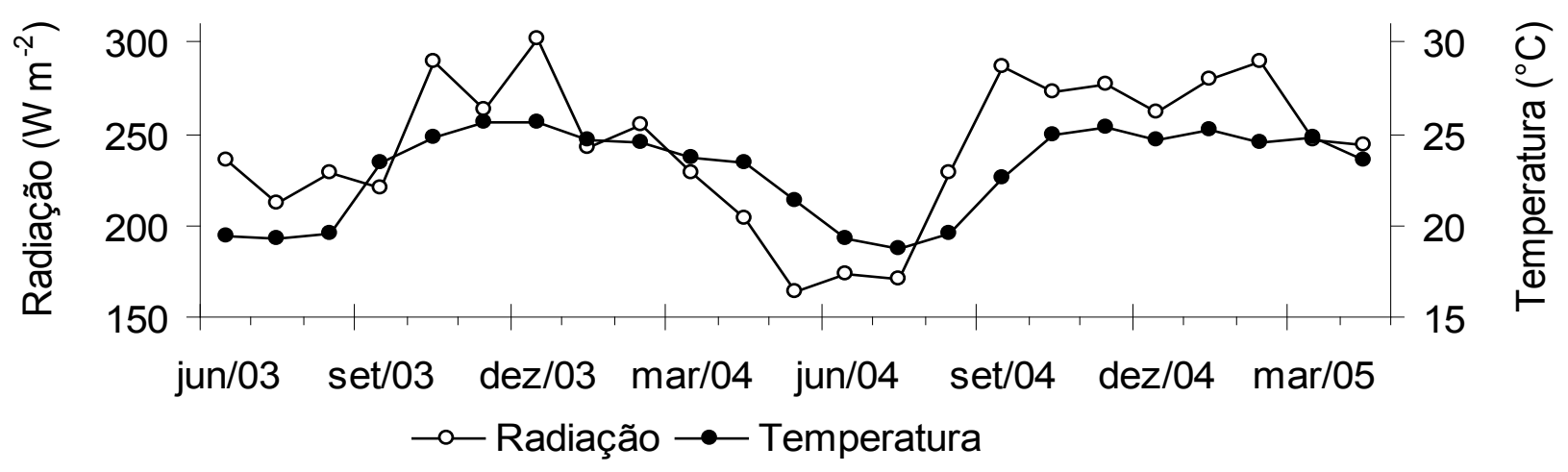

Figura 1. Variação mensal da radiação solar média $\left(\mathrm{W} \mathrm{m}^{-2}\right)$ e da temperatura média $\left({ }^{\circ} \mathrm{C}\right)$, no período de junho de 2003 a abril de 2005.

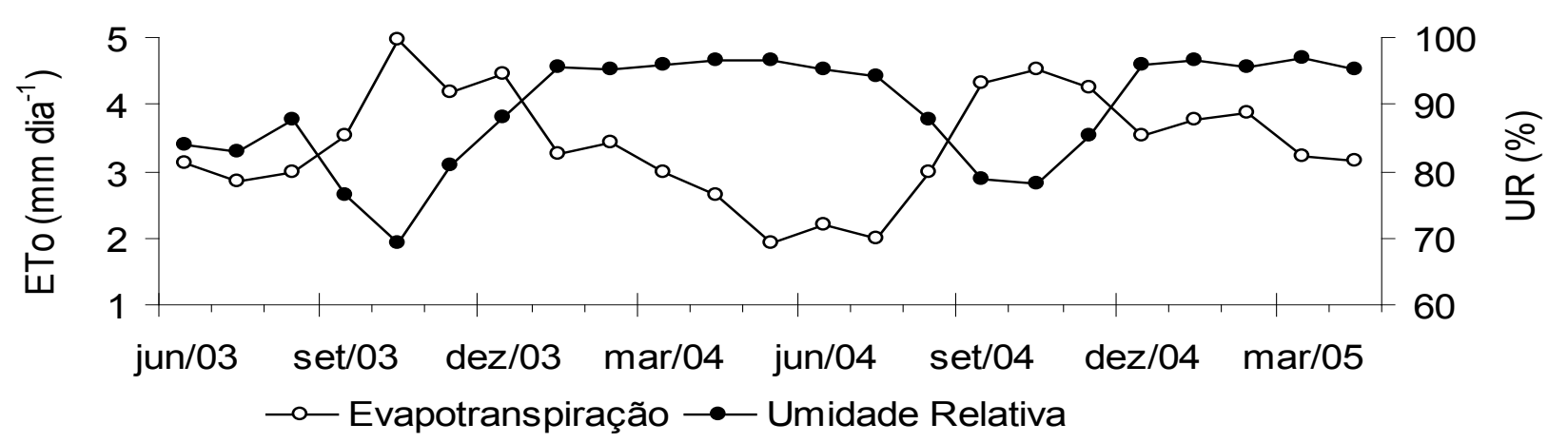

Figura 2. Variação média diária da evapotranspiração de referência ( $m m$ dia $\left.^{-1}\right)$ e mensal da umidade relativa (\%), no período de junho de 2003 a abril de 2005. 
Os valores médios de radiação solar apresentaram grandes oscilações durante todo $\mathrm{o}$ período experimental e variaram de 738 a $1.103 \mathrm{~W} \mathrm{~m}^{-2}$, nos períodos seco (entre abril e setembro) e chuvoso (entre outubro e março), respectivamente. Esse comportamento influenciou os valores de temperatura e, consequentemente, os de evapotranspiração de referência (ET0). Os valores médios de temperatura durante o experimento variaram de 18,7 a $25,6{ }^{\circ} \mathrm{C}$, sendo máximo entre os meses de outubro e março e mínimo entre os meses de abril e setembro. Os valores médios mensais de ET0 durante o estudo variaram de 1,92 a 4,98 $\mathrm{mm} \mathrm{dia}^{-1}$, sendo mínimo em maio de 2004 e máximo em outubro de 2003. Os valores médios de umidade relativa variaram entre 69 e 97\%. O comportamento da umidade relativa foi o oposto da radiação solar e da temperatura, observando-se valores máximos entre os meses de dezembro e maio e mínimos entre os meses de junho e novembro.

No Quadro 1, verifica-se, em geral, que o capimestrela apresentou maior $(\mathrm{p}<0,05)$ teor de proteína bruta (PB), seguido do capim-pioneiro. Santos et al. (2003), avaliando diversas forrageiras irrigadas no município de Recife, PE, verificaram que Pioneiro foi o capim que apresentou maior teor de PB $(10,2 \%)$, seguido dos capins Tanzânia (7,3\%), Marandu $(7,2 \%)$ e Mombaça $(7,0 \%)$, que não diferiram entre si. O teor de PB encontrado no capim-estrela foi próximo ao observado na literatura (ALVIM et al., 2003 e CECATO et al., 2001). No caso do capimxaraés existem poucos trabalhos na literatura, porém, Euclides (2002) encontrou teor de PB de 10,3\%. Os valores apresentados por esses autores foram maiores que os encontrados no presente trabalho, em razão, possivelmente, da avaliação ter sido somente realizada nas estações primavera e verão.

Segundo Machado et al. (1998), a variação do teor de PB entre os cultivares de uma mesma espécie e de idade semelhante é pequena. Estabelecendo comparações entre os cultivares da espécie Panicum maximum, observa-se que, independentemente da lâmina de irrigação, não houve diferença $(p>0,05)$ entre seus teores de $\mathrm{PB}$, o que concorda com os relatos do autor citado acima. $\mathrm{O}$ mesmo, porém, não foi verificado para os cultivares da espécie Brachiaria brizantha, pois o capim-marandu apresentou maior $(p<0,05)$ teor de PB em relação ao capim-xaraés, dentro de várias lâminas de irrigação.

As equações para estimativa do teor de PB das gramíneas forrageiras em função das lâminas de irrigação estão apresentadas na Figura 3. Observase que todas as forrageiras responderam à lâmina de irrigação de forma linear e negativa $(p<0,05)$, ou seja, com o aumento da lâmina de irrigação houve redução do teor de PB. O capim-estrela foi o mais responsivo à lâmina de irrigação, conforme observado em seu coeficiente de regressão $\left(\beta_{1}\right)$, seguido dos capins, Marandu, Pioneiro, Xaraés, Tanzânia e Mombaça.

Cunha et al. (2007), avaliando o capim-tanzânia, também encontraram menores teores de PB nos tratamentos que receberam maiores lâminas de irrigação. Isto se deve, provavelmente, a um maior crescimento da gramínea, resultando em maior alongamento do colmo e, portanto, em menor valor proteico, haja vista que esse componente possui menor valor nutritivo em relação as folhas.

Independentemente da lâmina de irrigação, observa-se, no Quadro 2, que o capim-estrela apresentou o maior $(p<0,05)$ teor de fibra em detergente neutro (FDN). Segundo Balsalobre (2002), as plantas do gênero Cynodon são caracterizadas por terem alta proporção de FDN, no entanto, apresentam teor de lignina relativamente baixo, o que lhes confere boa qualidade. Cecato et al. (2001), avaliando esse capim no município de Maringá, PR, na estação verão, encontraram teores de FDN variando de 70 a $67 \%$, nas doses de 0 e

Quadro 1. Teores médios de proteína bruta (\%), sob condições de corte, nas respectivas combinações de lâminas de irrigação e gramíneas forrageiras

\begin{tabular}{ccccccc}
\hline Gramínea & $0 \%$ ETc & $18 \%$ ETc & $45 \%$ ETc & $77 \%$ ETc & $100 \%$ ETc & $120 \%$ ETc \\
\hline Xaraés & $7,87 \mathrm{c}$ & $6,26 \mathrm{~b}$ & $4,84 \mathrm{c}$ & $5,00 \mathrm{c}$ & $4,91 \mathrm{c}$ & $4,62 \mathrm{c}$ \\
Mombaça & $7,71 \mathrm{c}$ & $6,53 \mathrm{~b}$ & $6,66 \mathrm{~b}$ & $5,05 \mathrm{c}$ & $5,43 \mathrm{bc}$ & $5,59 \mathrm{bc}$ \\
Tanzânia & $5,76 \mathrm{c}$ & $7,30 \mathrm{~b}$ & $6,98 \mathrm{~b}$ & $6,41 \mathrm{bc}$ & $4,97 \mathrm{c}$ & $4,98 \mathrm{bc}$ \\
Pioneiro & $8,67 \mathrm{bc}$ & $9,74 \mathrm{a}$ & $7,80 \mathrm{~b}$ & $8,18 \mathrm{a}$ & $6,09 \mathrm{bc}$ & $6,30 \mathrm{ab}$ \\
Marandu & $9,54 \mathrm{ab}$ & $7,50 \mathrm{~b}$ & $6,46 \mathrm{bc}$ & $6,60 \mathrm{ab}$ & $7,06 \mathrm{ab}$ & $5,01 \mathrm{bc}$ \\
Estrela & $10,84 \mathrm{a}$ & $9,40 \mathrm{a}$ & $9,48 \mathrm{a}$ & $7,59 \mathrm{ab}$ & $7,48 \mathrm{a}$ & $7,76 \mathrm{a}$ \\
\hline
\end{tabular}

Médias seguidas de letras diferentes na coluna diferem estatisticamente, pelo teste de Tukey $(p<0,05)$. 
$400 \mathrm{~kg} \mathrm{ha}^{-1}$ ano $^{-1}$ de nitrogênio, respectivamente. Os teores de FDN encontrados para os capins Mombaça e Tanzânia ficaram abaixo de 75\%. Euclides (1995), estudando diversos cultivares da espécie Panicum maximum, concluiu que valores de FDN inferiores a $55 \%$ são raros, valores superiores a $65 \%$ são comuns em tecidos novos, enquanto teores entre 75 e $80 \%$ são encontrados em forragem de maturidade avançada. Santos et al. (2003), trabalhando com diversas forrageiras irrigadas no município de Recife, PE, encontraram os seguintes teores de FDN: Pioneiro (68,1\%), Marandu (74,8\%), Mombaça (77,5\%) e Tanzânia (79,2\%). Para o capim-xaraés, Euclides (2002) citou valor de 73,4\%. No geral, os teores de FDN encontrados no presente trabalho foram inferiores aos encontrados na literatura, possivelmente pelo mesmo motivo, o fato de os valores de PB terem sido maiores.
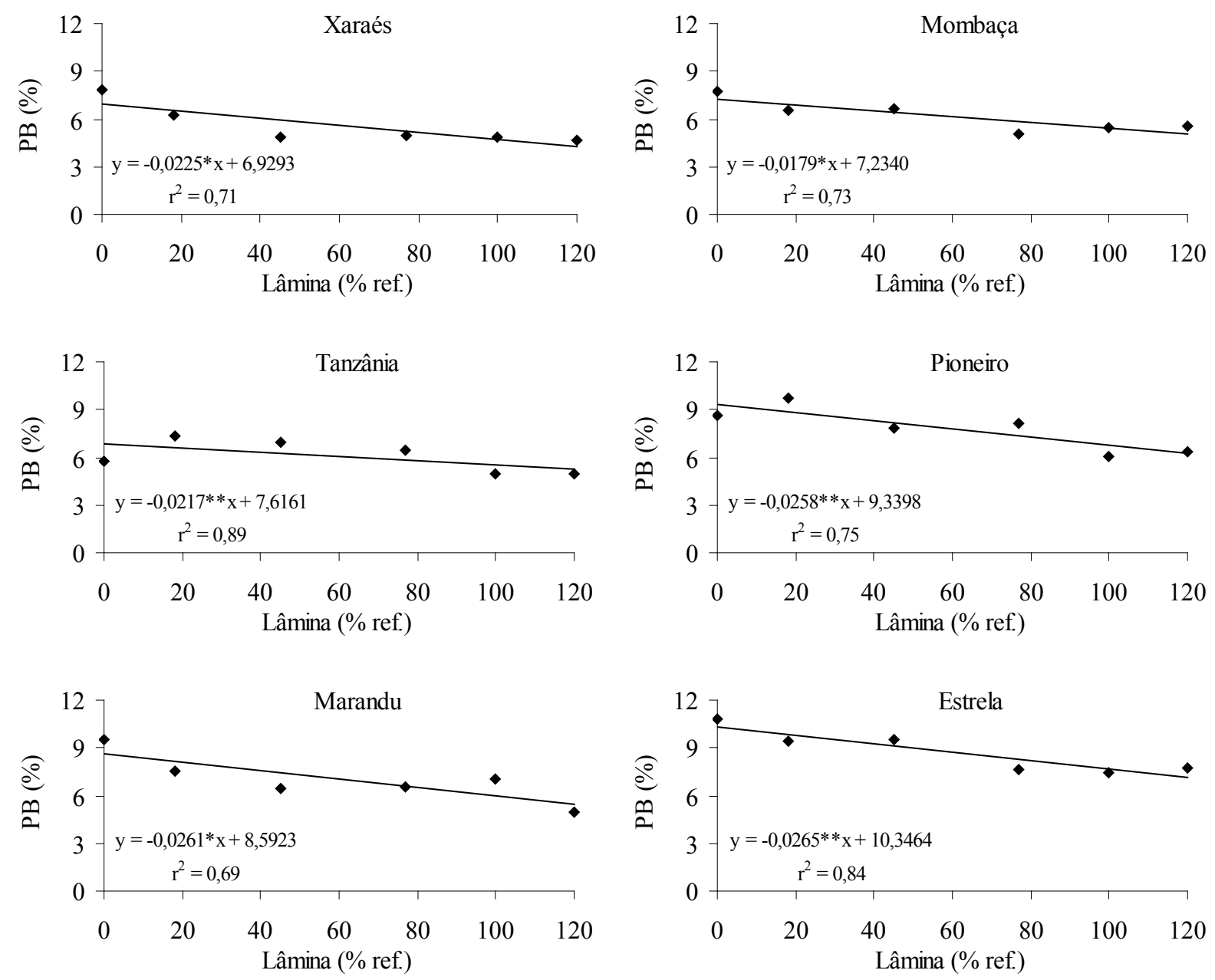

Figura 3. Estimativa dos teores de proteína bruta (PB em \%) de seis gramíneas forrageiras sob condições de corte, de acordo comas lâminas de irrigação (\% referência).

Quadro 2. Teores médios de fibra em detergente neutro (\%), sob condições de corte, nas respectivas combinações de lâminas de irrigação e gramíneas forrageiras

\begin{tabular}{ccccccc}
\hline Gramínea & $0 \%$ ETc & $18 \%$ ETc & $45 \%$ ETc & $77 \%$ ETc & $100 \%$ ETc & $120 \%$ ETc \\
\hline Xaraés & $70,87 \mathrm{~b}$ & $71,88 \mathrm{~b}$ & $74,80 \mathrm{ab}$ & $72,44 \mathrm{~b}$ & $72,60 \mathrm{~b}$ & $73,16 \mathrm{~b}$ \\
Mombaça & $71,26 \mathrm{~b}$ & $70,94 \mathrm{~b}$ & $70,14 \mathrm{c}$ & $72,53 \mathrm{~b}$ & $67,04 \mathrm{c}$ & $70,22 \mathrm{c}$ \\
Tanzânia & $74,10 \mathrm{a}$ & $71,95 \mathrm{~b}$ & $72,46 \mathrm{bc}$ & $71,44 \mathrm{bc}$ & $70,93 \mathrm{~b}$ & $72,97 \mathrm{~b}$ \\
Pioneiro & $69,88 \mathrm{~b}$ & $71,94 \mathrm{~b}$ & $72,36 \mathrm{c}$ & $69,59 \mathrm{c}$ & $71,30 \mathrm{~b}$ & $68,72 \mathrm{c}$ \\
Marandu & $72,10 \mathrm{ab}$ & $70,86 \mathrm{~b}$ & $71,69 \mathrm{c}$ & $71,64 \mathrm{bc}$ & $70,94 \mathrm{~b}$ & $69,41 \mathrm{c}$ \\
Estrela & $73,74 \mathrm{a}$ & $75,20 \mathrm{a}$ & $75,88 \mathrm{a}$ & $78,16 \mathrm{a}$ & $75,75 \mathrm{a}$ & $77,13 \mathrm{a}$ \\
\hline
\end{tabular}

Médias seguidas de letras diferentes na coluna diferem estatisticamente, pelo teste de Tukey $(p<0,05)$. 
$\mathrm{Na}$ Figura 4, estão apresentadas as equações para estimativa do teor de FDN das gramíneas forrageiras, em função das lâminas de irrigação. Observa-se que os capins da espécie Panicum maximum, Mombaça e Tanzânia, não responderam $(p>0,05)$ à lâmina de irrigação. Cunha et al. (2007), no município de Viçosa, MG, e Sória (2002), no município de Piracicaba, SP, também não encontraram respostas do teor de FDN do capim-tanzânia ao aumento da lâmina de irrigação. As demais forrageiras avaliadas responderam de forma quadrática $(p<0,05)$ e os valores máximos retirados das equações de regressão foram para as lâminas de irrigação de 72, 48, 34 e 88\% da referência, para os capins Xaraés, Pioneiro, Marandu e Estrela, respectivamente. Barreto et al. (2001), avaliando clones de capim-elefante, não encontraram efeito da irrigação no teor de FDN, porém, alguns autores relatam que as plantas submetidas a estresse hídrico apresentam menor teor de parede celular (WILSON, 1983; HALIM et al., 1989).

Observa-se, no Quadro 3, que Marandu e Estrela
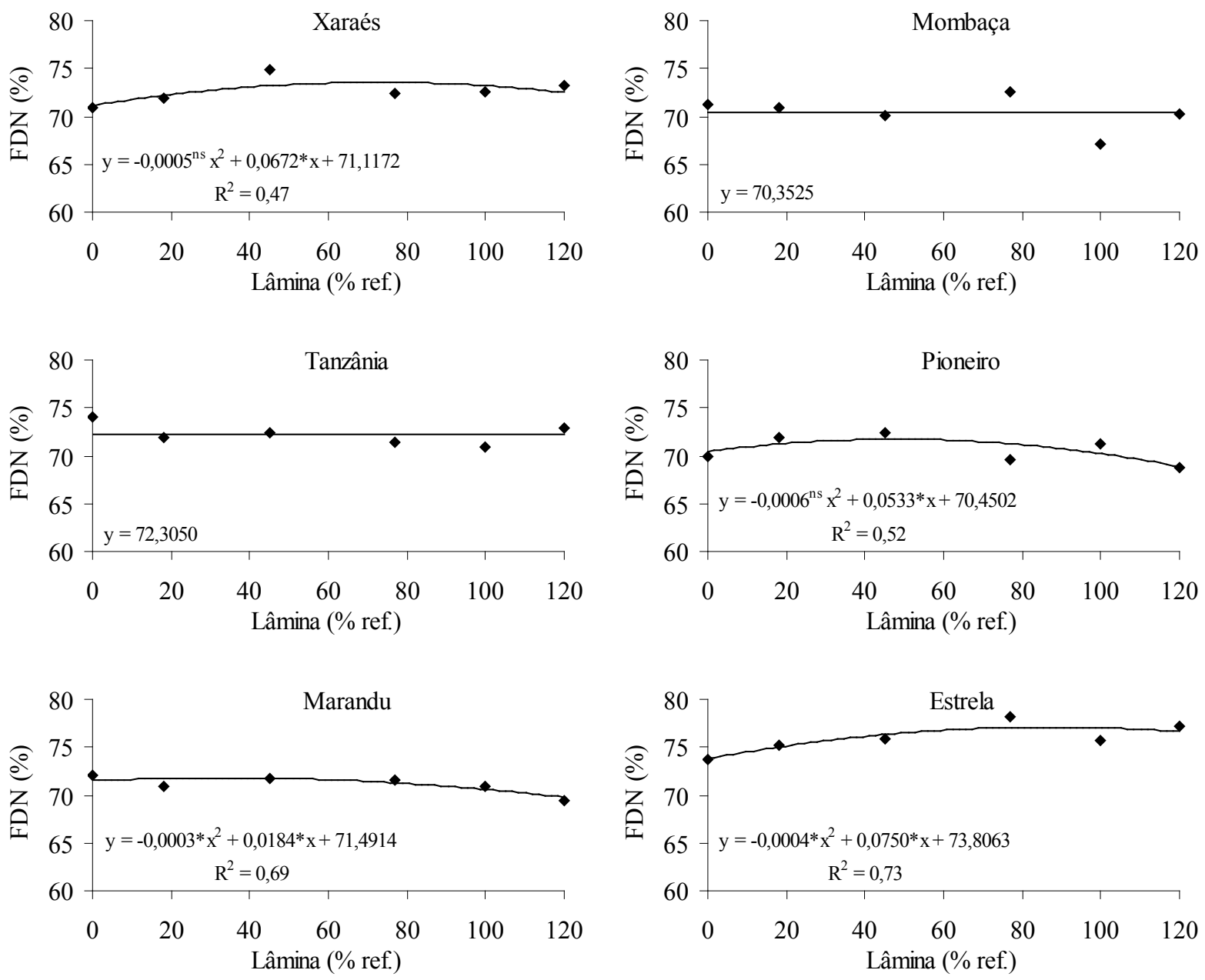

Figura 4. Estimativa dos teores de fibra em detergente neutro (FDN em \%) de seis gramíneas forrageiras sob condições de corte, em função das lâminas de irrigação (\% referência).

Quadro 3. Valores médios de digestibilidade in vitro da matéria seca (\%), sob condições de corte, nas respectivas combinações de lâminas de irrigação e gramíneas forrageiras

\begin{tabular}{ccccccc}
\hline Gramínea & $0 \%$ ETc & $18 \%$ ETc & $45 \%$ ETc & $77 \%$ ETc & $100 \%$ ETc & $120 \%$ ETc \\
\hline Xaraés & $54,81 \mathrm{~b}$ & $56,51 \mathrm{ab}$ & $52,01 \mathrm{~b}$ & $52,36 \mathrm{~b}$ & $51,84 \mathrm{~b}$ & $53,69 \mathrm{ab}$ \\
Mombaça & $49,17 \mathrm{c}$ & $48,72 \mathrm{c}$ & $46,36 \mathrm{c}$ & $43,13 \mathrm{c}$ & $43,33 \mathrm{c}$ & $45,47 \mathrm{c}$ \\
Tanzânia & $47,94 \mathrm{c}$ & $50,31 \mathrm{c}$ & $51,41 \mathrm{~b}$ & $50,41 \mathrm{~b}$ & $49,37 \mathrm{bc}$ & $46,20 \mathrm{c}$ \\
Pioneiro & $47,30 \mathrm{c}$ & $52,61 \mathrm{bc}$ & $50,22 \mathrm{bc}$ & $48,81 \mathrm{~b}$ & $46,10 \mathrm{c}$ & $48,82 \mathrm{bc}$ \\
Marandu & $61,32 \mathrm{a}$ & $60,98 \mathrm{a}$ & $62,80 \mathrm{a}$ & $62,09 \mathrm{a}$ & $60,38 \mathrm{a}$ & $57,76 \mathrm{a}$ \\
Estrela & $37,34 \mathrm{~d}$ & $38,81 \mathrm{~d}$ & $37,95 \mathrm{~d}$ & $34,77 \mathrm{~d}$ & $35,16 \mathrm{~d}$ & $38,91 \mathrm{~d}$ \\
\hline
\end{tabular}

Médias seguidas de letras diferentes na coluna diferem estatisticamente, pelo teste de Tukey $(p<0,05)$. 
foram os capins que apresentaram maior $(p<0,05)$ e menor $(p<0,05)$ digestibilidade in vitro da matéria seca (DIVMS), respectivamente. O capim-estrela teve menor DIVMS pelo fato de possuir maior FDN. Já, com relação ao capim-marandu, isso foi devido aos moderados valores de PB e FDN. Gerdes et al. (2000) obtiveram valores médios de DIVMS de 65,5 e 62,3\%, para os capins Marandu e Tanzânia, respectivamente, porém, a diferença de 3,2 unidades percentuais não foi significativa pelo teste de Tukey a 5\% de probabilidade. Apesar disso, esses autores relataram que os cultivares da espécie Panicum maximum possuem DIVMS inferior ao das gramíneas do gênero Brachiaria. Os resultados do presente trabalho corroboram esse relato.

Os valores de DIVMS dos cultivares do gênero Panicum estão inferiores aos encontrados por Machado et al. (1998), que foram de 64,6 e 63,4\%, no período chuvoso e 64,8 e $66,9 \%$, no período seco, nos capins Mombaça e Tanzânia, respectivamente. Quanto à
DIVMS encontrada na Estrela, ela está abaixo dos valores obtidos por Cecato et al. (2001) $(61,2 \%)$ e Alvim et al. (2003) (50,7\%), que trabalharam com dose nitrogenada de $400 \mathrm{~kg} \mathrm{ha}^{-1} \mathrm{ano}^{-1}$, no município de Coronel Pacheco, MG. Sória (2002), utilizando maiores doses de adubo nitrogenado, observou maiores valores de DIVMS, concluindo que a aplicação desse adubo traz benefícios não apenas na quantidade produzida, mas também na qualidade, pois a digestibilidade é um dos melhores previsores da qualidade da forragem.

$\mathrm{O}$ efeito proporcionado pelo aumento da lâmina de irrigação na DIVMS foi dependente da gramínea (Figura 5). Verificou-se que a lâmina de irrigação não influenciou $(p>0,05)$ os capins Xaraés, Pioneiro e Estrela, proporcionou efeito linear negativo $(p<0,05)$ no capim-mombaça e quadrático nos capins Tanzânia e Marandu, cujos valores máximos retirados das equações de regressão foram para as lâminas de irrigação de 54 a $47 \%$ da referência.
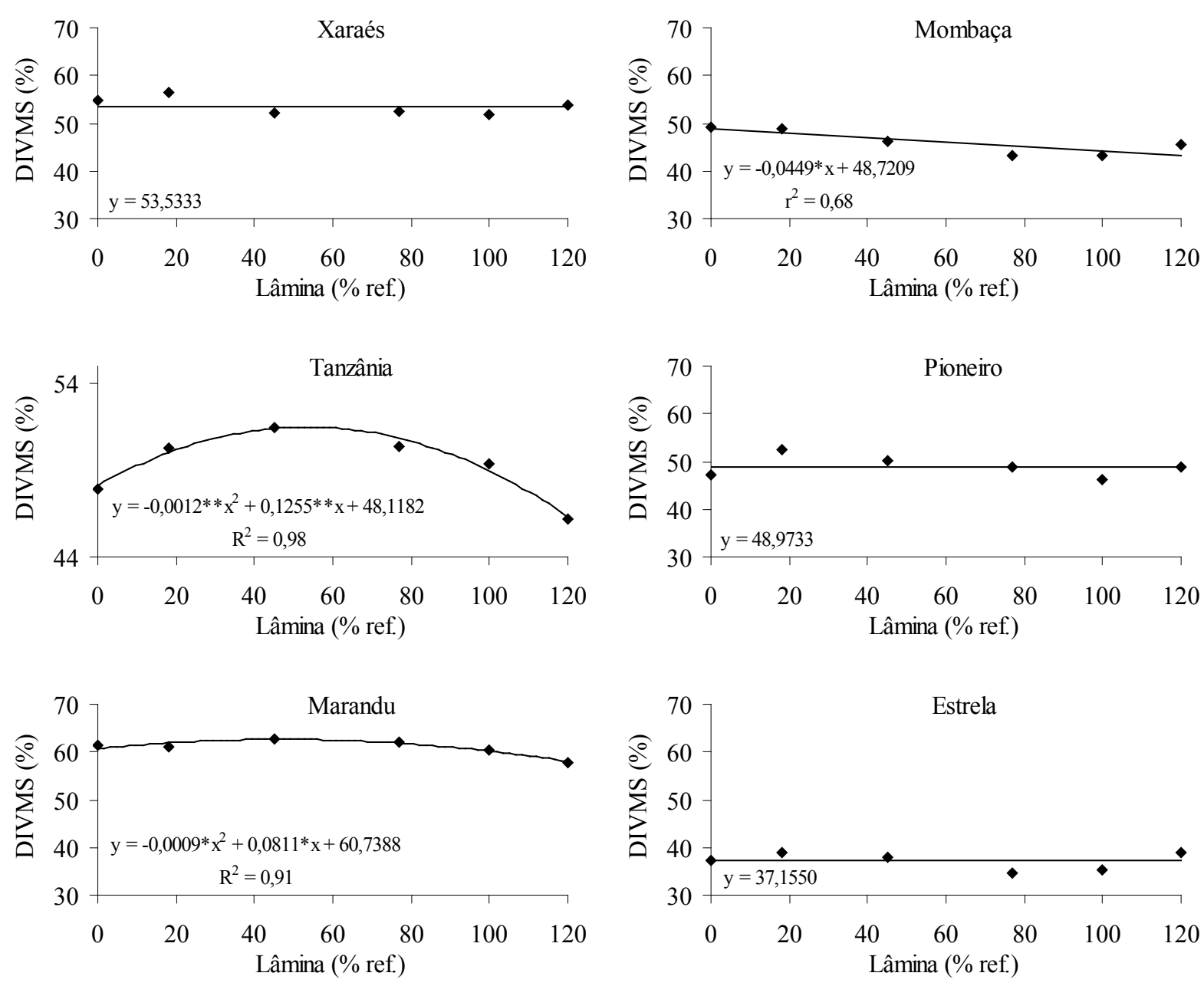

Figura 5. Estimativa dos valores de digestibilidade in vitro da matéria seca (DIVMS em \%) de seis gramíneas forrageiras sob condições de corte, em função das lâminas de irrigação (\% referência). 
Há na literatura certa controvérsia quanto à influência da lâmina de irrigação sobre a digestibilidade da forragem. Na literatura, Cunha et al. (2007) e Sória (2002) não encontraram respostas da DIVMS do capim-tanzânia e Barreto et al. (2001) não encontraram respostas da DIVMS do capimelefante. Todavia, Mislevy \& Everet (1981) e Dias Filho et al. (1991) verificaram que os tratamentos submetidos às maiores lâminas de irrigação apresentaram menores valores de DIVMS.

\section{CONCLUSÕES}

- O capim-estrela apresentou maior teor de proteína bruta e, independentemente da forrageira, o aumento da lâmina de irrigação reduziu seu teor.

- Quanto à fibra em detergente neutro, o capimestrela apresentou maior teor e a lâmina de irrigação não afetou seus teores nos capins Mombaça e Tanzânia e proporcionou efeito quadrático nos demais capins.

- Os capins Marandu e Estrela apresentaram maior e menor digestibilidade in vitro da matéria seca, respectivamente. A lâmina de irrigação reduziu a digestibilidade do capim-mombaça, proporcionou efeito quadrático nos capins Tanzânia e Marandu e não afetou as demais forrageiras.

\section{REFERÊNCIAS BIBLIOGRÁFICAS}

ALVIM, M. J.; BOTREL, M. A.; REZENDE, H.; XAVIER, D. F. Avaliação sob pastejo do potencial forrageiro de gramíneas do gênero Cynodon, sob dois níveis de nitrogênio e potássio. Revista Brasileira de Zootecnia, Viçosa, MG, v.32, n.1, p.47-54, 2003.

BALSALOBRE, M. A. A. Valor alimentar do capimtanzânia irrigado. Piracicaba: USP/ESALQ, 2002. 113 p. (Tese de doutorado).

BARRETO, G. P.; LIRA, M. A.; SANTOS, M. V. F. DUBEUX Jr., J.C. B. Avaliação de clones de capim-elefante (Pennisetum purpureum Schum.) e de um híbrido com o milheto (Pennisetum glaucum (L.) R. Br.) submetidos a estresse hídrico. 2. Valor nutritivo. Revista Brasileira de Zootecnia, Viçosa, MG, v.30, n.1, p.7-11, 2001.

CECATO, U.; SANTOS, G. P.; MACHADO, M.
A.; GOMES, L. H.; DAMASCENO, J. C.; JOBIM, C. C.; RIBAS, N. P.; MIRA, R. T.; CANO, C. C. P. Avaliação de cultivares do gênero Cynodon com e sem nitrogênio. Acta Scientiarum Agronomy, Maringá, v.23, n.4, p.781-788, 2001.

CUNHA, F. F.; SOARES, A. A.; PEREIRA, O. G.; MANTOVANI, E. C.; SEDIYAMA, G. C.; ABREU, F. V. S. Comparação bromatológica e digestibilidade in vitro da matéria seca do capim-tanzânia irrigado. Bioscience Journal, Uberlândia, v.23, n.2, p.25-33, 2007.

DIAS FILHO, M. B.; CORSI, M.; CUSATO, S.; CAMARÃO, A. P. Digestibilidade in vitro da matéria orgânica e teor de proteína bruta em Panicum maximum Jacq. cv. Tobiatã sob estresse hídrico. Pesquisa Agropecuária Brasileira, Brasília, v.26, n.10, p.1725-1729, 1991.

EMBRAPA - Empresa Brasileira de Pesquisa Agropecuária. Manual de métodos de análise de solo. 2.ed. Rio de Janeiro: EMBRAPA-CNPS, 1997. $212 \mathrm{p}$.

EUCLIDES, V. P. B. Novidades em forrageiras para a pecuária em regiões tropicais. In: SEMINÁRIO DE PASTURAS Y SUPLEMENTACION ESTRATÉGICA EM GANADO BOVINO, 4, 2002, Asuncion,Paraguay. Procedings... Asuncion: UNA, 2002. p.1-12.

EUCLIDES, V. P. B. Valor alimentício de espécies forrageiras do gênero Panicum. In: SIMPÓSIO SOBRE MANEJO DA PASTAGEM, 12, 1995, Piracicaba. Anais... Piracicaba: FEALQ, 1995. p.245-276.

GERDES, L.; MATTOS, H. B.; WERNER, J. C.; COLOZZA, M. T.; CUNHA, E. A.; BUENO, M. S.; POSSENTI, R. A.; SCHAMMASS, E. A. Composição química e digestibilidade da massa de forragem em pastagem irrigada de capim-aruana exclusivo ou sobre-semeado com mistura de aveia preta e azevém. Revista Brasileira de Zootecnia, Viçosa, MG, v.34, n.4, p.1098-1108, 2005.

GERDES, L.; WERNER, J. C.; COLOZZA, M. T.; POSSENTI, R. A.; SCHAMMASS, E. A. Avaliação de características de valor nutritivo das gramíneas forrageiras Marandu, Setária e Tanzânia nas estações 
do ano. Revista Brasileira de Zootecnia, Viçosa, MG, v.29, n.4, p.955-963, 2000.

GOMIDE. J. A. Produção de leite em regime de pasto. Revista Brasileira de Zootecnia, Viçosa, MG, v.22, n.4, p.591-613, 1993.

HALIM, R. A., BUXTON, D. R., HATTENDORF, M. J.; CARLSON, R. E. Water stress effects on alfafa forage quality after adjustment for maturity differences. Agronomy Journal, Madison, v.81, n.2, p.189-194, 1989.

HANKS, R. J.; KELLER, J.; RASMUSSEN, V. P.; WILSON, G. D. Line source sprinkler for continuous variable irrigation crop production studies. Soil Science of American Journal, Madison, v.40, n.3, p.426-429, 1976.

HEATH, M. E.; BARNES, R. F.; METCALFE, D. S. Forage, the science of grassland agriculture. 4.ed. Iowa: Iowa State University Press, 1985. 643p.

IBGE. Instituto Brasileiro de Geografia e Estatística. $<$ http://www.ibge.gov.br.2005> 31 ago. 2007.

MACHADO, A. O.; CECATO, U.; MIRA, R. T.; PEREIRA, L. A. F.; DAMASCENO, J. C. Avaliação da composição química e digestibilidade in vitro da matéria seca de cultivares e acessos de Panicum maximum Jacq. sob duas alturas de corte. Revista Brasileira de Zootecnia, Viçosa, MG, v. 27, n.5, p.1057-1063, 1998.

MISLEVY, P.; EVERETT, P. H. Subtropical grass species responses to different irrigation and harvest regimes. Agronomy Journal, Madison, v.[73, n.4, p.601-604, 1981.

RASSINI, J. R. Manejo de água de irrigação para alfafa (Medicago sativa L.). Revista Brasileira de Zootecnia, Viçosa, MG, v.30, n.6, p.1681-1688, 2001.

REIS, R. A.; RODRIGUES, L. R. A. Valor nutritivo de plantas forrageiras. Jaboticabal: Universidade Estadual Paulista, 1993. 26p.

RICHARDS, L. A. Methods of measuring soil moisture tension. Soil Science of American
Journal, Baltimore, v.68, n.1, p.95-112, 1949.

SANTOS, M. V. F.; DUBEUX Jr., J. C. B.; SILVA, M. C.; SANTOS, S. F.; FERREIRA, R. L. C.; MELLO, A. C. L.; FARIAS, I.; FREITAS, E. V. Produtividade e composição química de gramíneas tropicais na zona da mata de Pernambuco. Revista Brasileira de Zootecnia, Viçosa, MG, v.32, n.4, p.821-827, 2003.

SILVA, D. J.; QUEIROZ, A. C. Análises de alimentos (métodos químicos e biológicos). 3.ed. Viçosa: Imprensa Universitária, 2002. 235p.

SORIA, L. G. T. Produtividade do capim tanzânia (Panicum maximum Jacq. cv. Tanzânia) em função da lâmina de irrigação e de adubação nitrogenada. Piracicaba: USP/ESALQ, 2002. 11p. (Tese de doutorado)

TILLEY, J. M. A.; TERRY, R. A. A two-stage technique for the in vitro digestion of forage crops. Journal of the British Grassland Society, Oxford, v.18, n.2, p.104-111, 1963.

VAN SOEST, P. J. Nutritional ecology of the ruminant. 2. ed. Tthaca: Cornell University Press, 1994. 476p.

VANZELA, L. S.; HERNANDEZ, F. B. T.; GARGANTINI, P. E.; LIMA, R. C. Qualidade de forragem de caim-mombaça sob irrigação na região Oeste do Estado de São Paulo. In: CONGRESSO NACIONAL DE IRRIGAÇÃO E DRENAGEM, 16, 2006, Goiânia. Anais... Goiânia: ABEAS, 2006. CD-ROM.

VILELA, P. A. Uma visão sobre a produção intensiva de bovinos de corte com o uso do pivô central. In: SIMPÓSIO GOIANO SOBRE PRODUÇÃO DE BOVINOS DE CORTE, 1, 1999, Goiânia. Anais... Goiânia: CBNA, 1999. p.191-200.

WHITEMAN, P. C. Tropical pasture science. New York: Oxford University Press, 1980. 392p.

WILSON, J. R. Effects of water stress on in vitro dry matter digestibility and chemical composition of herbage of tropical pasture species. Australian Journal of Agricultural Research, Melbourne, v.34, n.4, p.377-390, 1983. 